\title{
Perda de substância do lábio inferior após anestesia pterigomandibular
}

\author{
Lower lip Substance Loss After Pterygomamandibular Anesthesia
}

Pérdida de la sustancia del labio inferior después de la anestesia pterigomamandibular

Jéssica da Mota Stripari ${ }^{*}$, Luiz Fernando Rodrigues Ferreira ${ }^{2}$, Pamela Leticia dos Santos ${ }^{2}$, Marcelo Augusto $\mathrm{Cini}^{2}$, Caio Peres Bellato², David Costa Moreira ${ }^{2}$, Marcus Vinicius Satoru

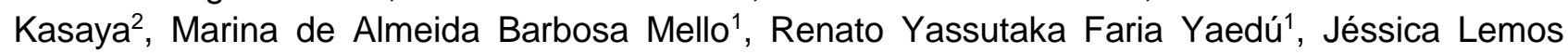
Gulinelli2.

\section{RESUMO}

Objetivo: Relatar o caso de extensa perda tecidual traumática do lábio por auto mordida após bloqueio do nervo alveolar inferior para exodontia de terceiro molar inferior incluso. Detalhamentos de Caso: Paciente gênero feminino, 20 anos de idade, leucoderma, sem alterações sistêmicas e psicológicas, compareceu à clínica para extração do elemento dentário 48 incluso. A paciente foi submetida à anestesia pterigomandibular sem intercorrências. Após o procedimento a paciente foi para sua casa ainda com o lábio anestesiado e acabou dormindo. Ao acordar notou que estava com o rosto e com a blusa de sangue, e ao olhar no espelho observou que havia perdido parte do lábio inferior e que provavelmente teria mastigado e engolido uma vez que ainda estava sob efeito da anestesia. A paciente procurou o serviço do Hospital onde foi submetida a um procedimento de cirúrgico pela equipe de cirurgia bucomaxilofacial e cirurgia plástica sob anestesia geral. Considerações finais: é de suma importância a explicação do cirurgião sobre o pósoperatório das cirurgias, sobre os cuidados com a anestesia local, o tempo de efeito de duração droga e os efeitos que ela pode causar enquanto se aguarda metabolização completa da solução em questão.

Palavras-chave: Anestesia local, Nervo mandibular, Lábio.

\begin{abstract}
Objective: To report the case of extensive traumatic self-bite traumatic tissue loss of the lip after blockage of the lower alveolar nerve for included lower third molar extraction. Case Details: A 20-year-old female patient, leukoderma, without systemic and psychological changes, attended the clinic for extraction of the included dental element 48. The patient underwent uneventful pterigomandibular anesthesia. After the procedure, the patient went home with her anesthetized lip and ended up sleeping. When she woke up, she noticed that she had her face and blood blouse, and when she looked in the mirror, she noticed that she had lost part of her lower lip and that she probably would have chewed and swallowed since she was still under anesthesia. The patient sought the service of the Hospital where she underwent a surgical procedure by the oral and maxillofacial surgery team and plastic surgery under general anesthesia. Final considerations: The surgeon's explanation of postoperative surgeries, local anesthetic care, the duration of drug duration and the effects it may cause pending complete metabolization of the solution in question is of paramount importance.
\end{abstract}

Keywords:. Local anesthesia, Mandibular nerve, Lip.

\section{RESUMEN}

Objetivo: informar el caso de una pérdida traumática extensiva del labio por auto mordida traumática después del bloqueo del nervio alveolar inferior para la extracción del tercer molar inferior incluida. Detalles del caso: una paciente de 20 años, leucoderma, sin cambios sistémicos y psicológicos, asistió a la clínica para extraer el elemento dental incluido 48. El paciente se sometió a anestesia pterigomandibular sin

\footnotetext{
${ }^{1}$ Hospital de Reabilitação de Anomalias Craniofaciais (HRAC-USP) Bauru-SP.

*E-mail: jessica_stripari@hotmail.com

2 Unisagrado - Bauru-SP
} 
incidentes. Después del procedimiento, la paciente se fue a su casa con el labio anestesiado y terminó durmiendo. Cuando se despertó, notó que tenía la cara y la blusa de sangre, y cuando se miró en el espejo, notó que había perdido parte de su labio inferior y que probablemente habría masticado y tragado porque todavía estaba bajo anestesia. La paciente buscó el servicio del Hospital, donde se sometió a un procedimiento quirúrgico por parte del equipo de cirugía oral y maxilofacial y cirugía plástica bajo anestesia general. Consideraciones finales: la explicación del cirujano sobre las cirugías postoperatorias, el cuidado de la anestesia local, la duración de la duración del fármaco y los efectos que puede causar hasta la metabolización completa de la solución en cuestión es de suma importancia.

Palabras clave: Anestesia local, Nervio mandibular, Labio

\section{INTRODUÇÃO}

A técnica de bloqueio do nervo alveolar inferior foi introduzida pelo cirurgião dentista $\mathrm{H}$. Raymond e o médico Willian Halsted em 1885, e consiste no bloqueio dos nervos alveolares inferiores, lingual e bucal (ALVAREZ GS, et al., 2013; COATES ML e CARRIE S, 2019; HARRIS L et al., 2012; BARTLETT G e MANSOOR J, 2016). O sucesso da anestesia na mandibula depende da localização da ponta da agulha ao forame mandibular, devendo estar próxima ao forame para uma administração correta e efetiva da droga anestésica na região pterigomandibular atingindo assim o nervo alveolar inferior (FOWLER S, et al., 2016; TANNER RB e HUBBELL JAE, 2019). Na literatura existem diversas métodos para realização da anestesia nesta região, encontrando-se: a técnica direta do pterigomandibular, a técnica indireta do pterigomandibular, bloqueio do nervo mandibular com a boca fechada conhecida como Akinosi e a bloqueio do tronco do nervo mandibular conhecido como Gow-Gates (KANAA MD, et al., 2012; KHOURY J e GRANT T, 2011). É preciso levar em conta que cada paciente pode apresentar uma alteração anatômica diferente desse nervo, desta maneira, independente da técnica anestésica escolhida no momento da anestesia, todas podem apresentar uma variável na sua taxa seu sucesso (UCHIKAWA Y, et al., 2012; WONG G, et al., 2019; YE W, et al., 2014).

Durante a anestesia do bloqueio anestésico do pterigomandibular podem ocorrer algumas lesões, atingindo o nervo alveolar inferior com maior recorrência em relação as outras estruturas adjacentes (RENTON T, et al., 2010; UGLESIC V, et al., 2019). Perfuração do nervo alveolar, trismo, hematoma e fratura de agulha são algumas das intercorrências que podem ocorrer durante o procedimento anestésico. A perfuração pode existir devido a se utilizar a agulha longa nessa técnica e acabar perfurando o nervo, o Hematoma na mandibula pode acontecer após algum dano causado a veia alveolar inferior ou artéria alveolar inferior, já trismo é uma complicação que pode acontecer devido a introdução do componente anestésico nos músculos adjacentes (UCHIKAWA Y, et al., 2012; SPIVAKOVSKY S, 2019). Outra complicação é a fratura das agulhas, por incorreta execução da técnica ou escolha errada do tipo de agulha (EBRAHIMI A, et al., 2011). O traumatismo dos lábios, bochecha e da língua é frequente após o paciente morder ou mastigar inadvertidamente essas estruturas enquanto ainda anestesiado (BARTLETT $G$ e MANSOOR J, 2016; COATES ML e CARRIE S, 2010).

A mordedura ou mastigação acidental do lábio, ocorre frequentemente com o paciente ainda anestesiado e pode se dizer que é uma complicação da anestesia residual dos tecidos moles. Felizmente, a maioria dos pacientes não apresentam problemas relacionados com anestesia prolongada dos tecido moles, mas quando ocorre os pacientes são crianças, idosos ou pessoas que apresentam incapacidade mental ou física (HARRIS L et al., 2012; COATES ML e CARRIE S, 2019). Na maioria das vezes, os problemas relacionados a anestesia dos tecidos moles envolvem o lábio inferior, e isso pode ser devastador para o paciente (FOWLER S, et al., 2016; RENTON T, et al., 2010). A causa primária é o fato de os tecidos moles ficarem anestesiados por um tempo significantemente maior do que a anestesia pulpar (EBRAHIMI A, et al., 2011). Os pacientes odontológicos que recebem anestesia local durante o tratamento geralmente são dispensados do consultório com alguma dormência residual dos tecidos moles (ESPITALIER F, et al., 2013; LUBEK JE e ORD RA, 2013). O trauma a tecidos moles anestesiados pode levar a perda da estrutura labial, consequentemente a dor e o inchaço serão significantes quando o efeito anestésico melhorar. Uma criança 
pequena ou indivíduos deficientes podem não suportar estas situações, podendo haver problemas de comportamento. A possibilidade de infeção se desenvolver é remota na maioria das vezes (KUNG J, et al., 2015; SPIVAKOVSKY S, 2019).

Para a prevenção um anestésico local de curta duração deve ser selecionado para procedimentos rápidos, na saída do paciente um rolo de algodão pode ser posto entre os lábios e os dentes se eles ainda estiverem anestesiados no momento, e alertar o paciente e o responsável a evitar comer, beber líquidos quentes, e mordem os lábios ou língua para testar a anestesia (KANAA MD, et al., 2012; FOWLER S, et al., 2016).

O tratamento do paciente com alta lesão dos tecidos moles é sintomático; deve fazer uso de analgésico para dor, se necessário, e antibióticos, no caso de uma infecção indesejável se desenvolver, fazer bochechos com solução salinas mornas ajuda a diminuir o inchaço que pode estar presente (KUNG J, et al., 2015). E em caso de lesão extensa (perda de tecido mole) realizar sutura e reconstrução do local (ALVAREZ GS, et al., 2013; TANNER RB e HUBBELL JAE, 2019).

Diante destas informações, o objetivo é relatar o caso de uma paciente que ingeriu uma parte próprio lábio após um procedimento de extração dentaria, e mostrar a importância das orientações do cirurgião dentista no pós operatório imediato, mais especificamente em relação ao efeito e a duração da droga anestésica, afim de minimizar intercorrências no pós operatório.

\section{RELATO DE CASO}

Paciente gênero feminino, 20 anos de idade, leucoderma, sem alterações sistêmicas e psicológicas, compareceu à clínica para extração do elemento dentário 48 incluso. A paciente foi submetida à anestesia pterigomandibular com infiltração de dois tubetes anestésicos de cloridrato de Articaína 4\% com Epinefrina 1:200.000. (Nova DFL® Rio de Janeiro - Brasil). O procedimento de extração dentária ocorreu sem intercorrências.

Depois do procedimento, a mesma voltou para sua casa sob o efeito da droga anestésica, como acontece com todos os pacientes submetidos a uma extração dentaria. Porem a paciente acabou dormindo devido ao cansaço causado pelo estresse da cirurgia. Ao acordar notou-se que havia sangue em seu rosto e em sua blusa ao olhar no espelho a paciente percebeu que havia mordido e ingerido a porção inferior do lábio. (Figuras 1A E 2B). Procurou imediamente o serviço de Cirurgia e Traumatologia Bucomaxilofacial (CTBMF) do Hospital, onde foi atendida primeiramente pelo médico plantonista do hospital que realizou uma avaliação da paciente, ao exame físico, observou que o ferimento que abrangia pele, vermelhão do lábio e porção do músculo orbicular dos lábios, em uma conversa com a paciente ela chorando relatou que havia realizado uma cirurgia de extração dentaria do dente 48 e acabou dormindo chegando em casa e quando acordou estava sem partes do lábio. O médico então confirmou que a paciente havia perdido uma quantidade significada de substancia labial e que necessitaria de uma reconstrução plástica para devolver sua estética e função.

Foi então chamada a equipe de cirurgia bucomaxilofacial do hospital que conversou com a paciente e explicou a situação em questão e explicou o efeito que a droga anestésica tinha causado no seu organismo e o porquê dela não ter acordado enquanto mastigava seu próprio lábio. Foi traçado um plano de tratamento onde seria realizado a cirurgia por profissionais da equipe da cirurgia bucomaxilofacial juntamente com a equipe de cirurgia plástica do hospital, a paciente então foi internada para início do procedimento cirúrgico onde foi realizado a reconstrução labial com sutura sob anestesia geral (Figura 2A e 2B).

$\mathrm{Na}$ reconstrução labial foi utilizado um retalho local, incluindo musculatura inervada, oferecendo uma mistura entre textura cor e espessura dos tecidos. Foi mantido a relação do lábio inferior com o lábio superior e também foi respeitado a linha de transição entre o vermelho do lábio e pele proporcionando uma melhor estética para paciente, foi realizado uma única sutura para reaproximar a borda do vermelhão do lábio com precisão, e os tecidos profundos foram fechados em camadas, seguidas por fechamento da mucosa com sutura 4-0 cromada e fechamento da pele com náilon 6-0. 
A paciente após a cirurgia ficou internado no hospital por um dia e meio para controle dos cirurgiões sobre o caso. A prescrição medicamentosa foi realizada com antibiótico (Amoxicilina 500mg, 8/8 horas por 7 dias), anti-inflamatório (ibuprofeno $600 \mathrm{mg} .8 / 8$ horas por 3 dias), analgésico (dipirona sódica $500 \mathrm{mg}$ por 3 dias) e colutorio (digluconato de clorexidina $0,12 \%$ por 7 dias). Após o retorno de 6 meses da paciente ao hospital a pedido do cirurgião plástico, foi observado que a paciente se apresenta com o lábio inferior reconstruído, fase de cicatrização finalizada, função e estética devolvidos a paciente, ausência sintomatologia dolorosa e infeção no local da cirurgia, sendo recomendado pelo cirurgião alta hospitalar. (Figuras 3A e 3B).

Figura 1A e 1B - Aspecto clínico inicial evidenciando a perda de substância labial inferior direito.

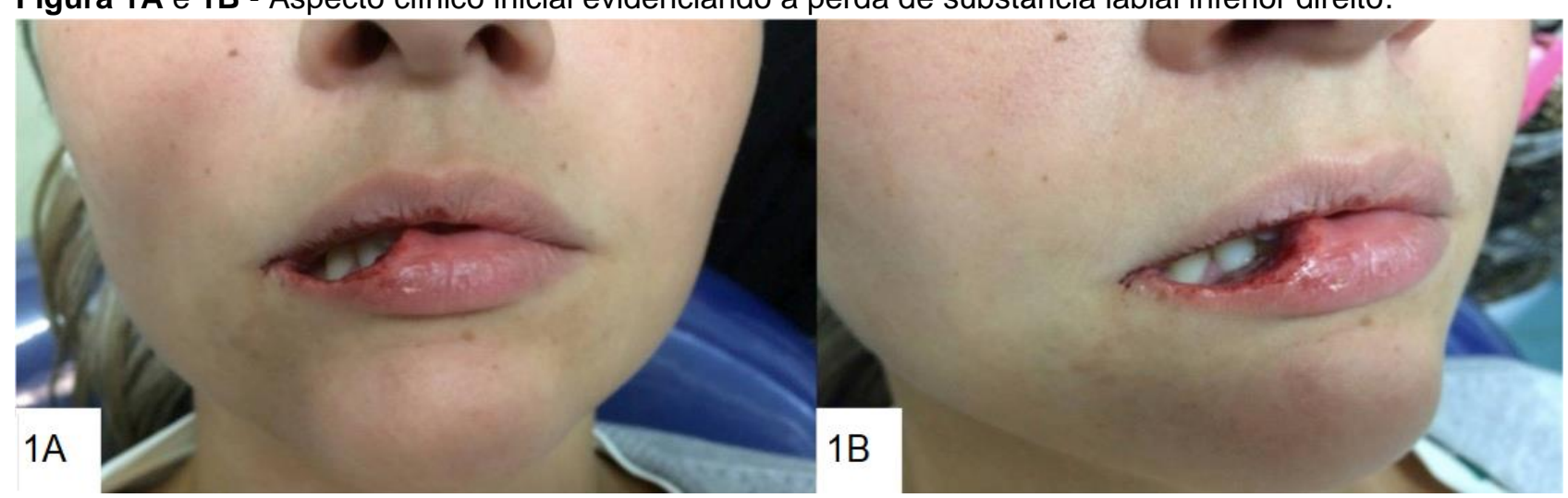

Fonte: Gulinelli, JL et al., 2018

Figura 2A e 2B - Reconstrução labial por descolamento de retalho realizado pelo cirurgião plástico.

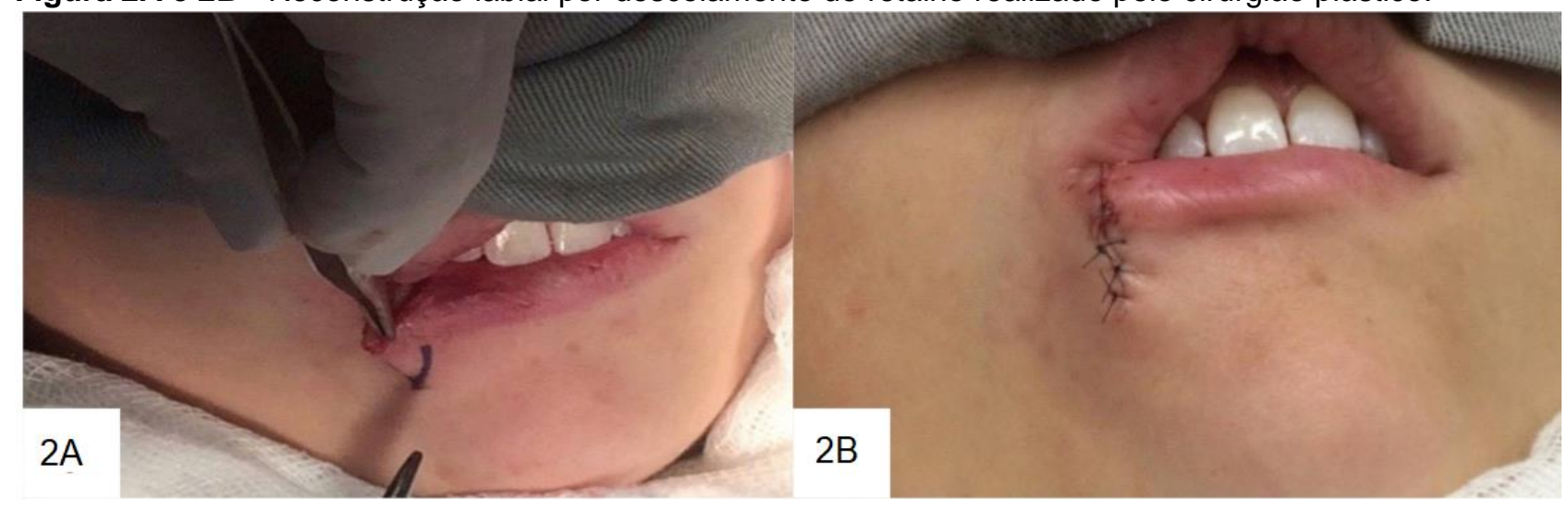

Fonte: Gulinelli, JL et al., 2018

Figura 3A e 3B - Controle Clinico de seis meses após reconstrução labial.

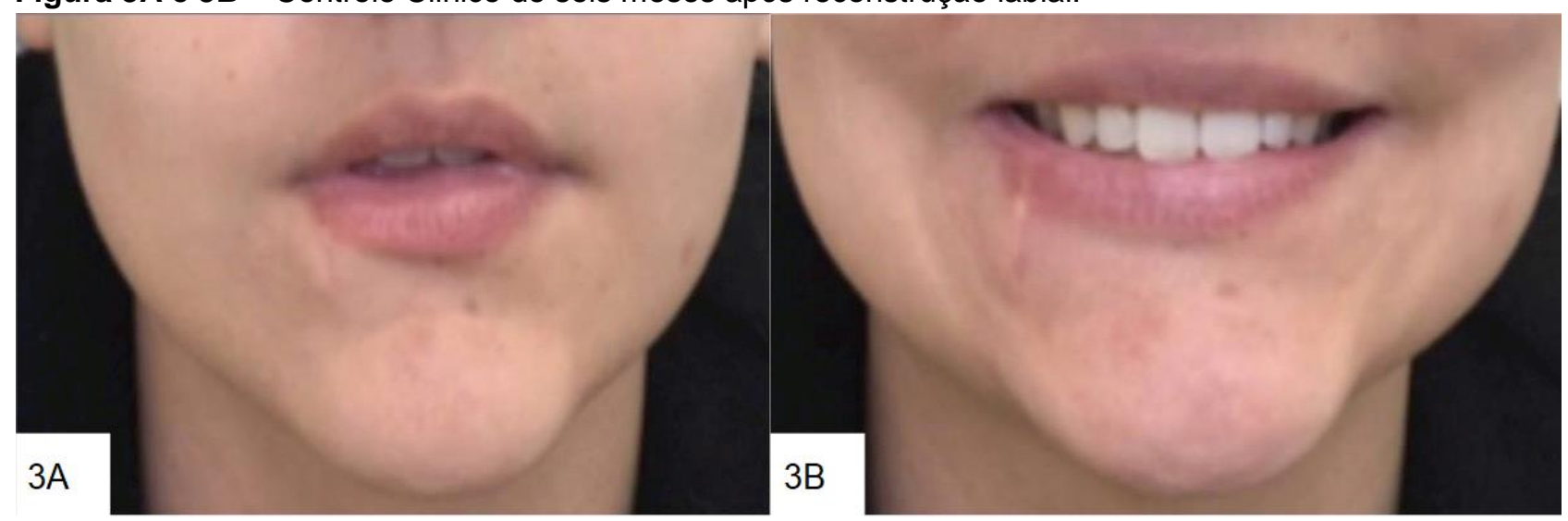

Fonte: Gulinelli, JL et al., 2018 


\section{DISCUSSÃO}

A maioria dos defeitos labiais ocorre como resultado de trauma, infecção, queimaduras ou após uma excisão cirúrgica das lesões (KHOURY J, et al., 2015 KHOURY J e GRANT T, 2011; YE W, et al., 2014; UGLESIC V, et al., 2019). No entanto, de acordo com a grande maioria dos estudos, a etiologia mais comum da lesão labial é a mordida humana (HARRIS L, et al., 2012; YE W, et al., 2014). O lábio inferior é o local mais comumente envolvido. Isso pode ser explicado pela posição do lábio inferior na face, que o torna entre as partes mais proeminentes da face. Após a estabilização inicial, as feridas faciais devem ser avaliadas quanto ao tipo, tamanho e profundidade das feridas e presença de infecção (UCHIKAWA Y, et al., 2012; WONG G, et al., 2019; TANNER RB e HUBBELL JAE, 2019). A classificação de Lackmann de ferimentos faciais baseados na extensão aparece no Quadro 1. O caso descrito pode ser classificado como tipo IIIA com alguma perda de tecido na área labial.

Quadro 1 - Classificação de Lackmann de lesões de mordida facial.

\begin{tabular}{|l|l|}
\hline I & Lesão superficial sem envolvimento muscular \\
\hline II A & Lesão profunda com envolvimento muscular \\
\hline II B & Lesão de espessura total da bochecha ou lábio com comprometimento da mucosa bucal \\
\hline III A & Lesão profunda com defeito tecidual (avulsão completa) \\
\hline III B & Lesão avulsiva profunda expondo cartilagens nasais e auriculares \\
\hline IV A & Lesão profunda com nervo facial cortado e / ou ducto parotídeo \\
\hline IV B & Lesão profunda com fratura óssea concomitante \\
\hline
\end{tabular}

Fonte: Gulinelli JL, 2018.

O manejo dessas lesões permite que as feridas reparem por fechamento primário o qual otimiza os resultados estéticos. Após vários anos de discussão, parece haver algum consenso sobre as diretrizes para o tratamento de feridas faciais por mordida (KHOURY $\mathrm{J}$ e GRANT T, 2011; MALAMED SF, 2011). Os principais passos são os seguintes: Lavagem adequada da ferida por irrigação; desbridamento meticuloso, mas não exagerado, de tecido desvitalizado; fechamento primário da ferida, exceto em casos de alto risco; antibioticoterapia adequada e imunização contra o tétano e a raiva quando necessário (KHOURY JN, et al., 2011; ALVAREZ GS, et al., 2013; HARRIS L, et al., 2012; SPIVAKOVSKY S, 2019). A prática atual enfatiza que a irrigação completa de feridas de mordida contaminada diminuiria significativamente a carga bacteriana, removeria o material particulado e reduziria a taxa de infecção (COATES ML e CARRIE S, 2019; RENTON T, et al., 2010; BARTLETT G e MANSOOR J, et al., 2016).

As técnicas de irrigação variam da irrigação manual utilizando uma seringa de 20 a $35 \mathrm{~mL}$ (agulha de 18 a 20G) até a lavagem de jato pulsátil (pressão de 50 a 70psi), a solução salina normal é o agente irrigador de primeiro escolha, uma vez que não interfere com a cicatrização normal da ferida (FOWLER S, et al., 2016; ESPITALIER F, et al., 2013). Lesões por mordida humana carregam o risco de serem infectadas com a flora bacteriana da cavidade oral e estas infecções são de natureza polimicrobiana. Isso muitas vezes leva ao desbridamento inicial e ao retardo do fechamento devido ao medo de infecções da ferida (YE W, et al., 2014; WONG G, et al., 2019; UCHIKAWA Y, et al., 2012). O tratamento profilático com antibióticos de amplo espectro e o fechamento primário da ferida da mordida permanecem como áreas de controvérsia. No entanto, o fechamento tardio só deve ser reservado para certas feridas de alto risco ou já infectadas (EBRAHIMI A, et al., 2011; KUNG J, et al., 2015). O fato de a maioria dos pacientes ter boa cicatrização da ferida após suturas primárias é devido ao bom suprimento sanguíneo na região facial, o que aumenta a resistência do hospedeiro (LUBEK JE e ORD RA, 2013).

Cuidados pós-operatórios e acompanhamento são importantes para otimizar os resultados, (SPIVAKOVSKY S, 2019). Manter a ferida limpa possibilita uma reepitelização mais rápida, a reconstrução das fibras leva tempo e suturar a ferida mantem a pele junta, até que novo tecido conjuntivo seja formado (KHOURY J e GRANT T, 2011). A limpeza diária com peróxido de hidrogênio diluído, curativos com sulfato de polimixima $B$ e pomada bacitracina de zinco (Polysporin) é um protocolo padrão, e os pacientes devem evitar a exposição ao sol durante os primeiros 6 meses após a lesão. (MALAMED SF, 2011) 
A cirurgia reconstrutiva do lábio, permite sua reconstrução por meio de uma variedade de técnicas e procedimentos cirúrgicos (HARRIS L et al., 2011; LUBEK JE e ORD RA, 2013; ALVAREZ GS, 2013). A anatomia dos lábios envolve uma transição de tecido mucoso para pele e com isto as cicatrizes que afetam o orbicular da boca podem resultar em dificuldades funcionais, os bloqueios nervosos são uteis em resultar feridas que envolvem o lábio, para evitar a distorção causada ao injetar diretamente na ferida. Uma sutura única deve ser colocada inicialmente para reaproximar a borda do vermelhão com precisão, e os tecidos profundos são fechados em camadas, seguidas por fechamento da mucosa com sutura 4-0 cromada e fechamento da pele com náilon 6-0 (EBRAHIMI A, et al., 2011; YE W, et al., 2014; ESPITALIER F, et al., 2013). Os defeitos avulsivos dos lábios requerem atenção especial, pois até um quarto dos lábios pode ser fechado por primeira intensão com resultados funcionais e estéticos aceitáveis, já as lesões que envolvem uma quantidade de perda de tecido podem ser reconstruídas com uma variedade de retalhos (LUBEK JE e ORD RA, et al., 2013; ALVAREZ GS, et al., 2013).

O desbridamento cirúrgico do tecido desvitalizado deve ser mantido ao mínimo na área facial, áreas de referência, como a borda vermelhão, sulco nasolabial e sobrancelhas devem ser mantidas. (UGLESIC V, et al., 2019). Princípios para a reconstrução do lábio incluem as partes remanescentes do lábio, empréstimo de tecido do lábio oposto e/ou da bochecha, e avanço dos retalhos adjacentes (UCHIKAWA Y, et al., 2012). Os principais objetivos da reconstrução são a restauração da competência bucal, a manutenção da abertura bucal e a restauração das relações anatômicas normais. (HARRIS L, et al., 2019; UGLESIC V, et al., 2019).

\section{CONSIDERAÇÕES FINAIS}

É possível concluir que é e suma importância a explicação do cirurgião dentista sobre o pós operatório das cirurgias bucomaxilofaciais, sendo elas tanto cirurgias orais maiores como cirurgias orais menores, muitos cirurgiões dentistas dedicam a sua atenção para explicações sobre a área do local da cirurgia e os procedimentos que podem ou não serem realizados após a extração para melhorar sua cicatrização, porém muito pouco se abrange sobre os cuidados com a anestesia local, o tempo de efeito de duração droga e os efeitos que ela causará enquanto se aguarda metabolização completa da solução em questão. Esse trabalho serve como exemplo de como é imprescindível a explicação de todas as etapas e riscos que o paciente corre após a realização de um procedimento cirúrgico.

\section{REFERÊNCIAS}

1. ALVAREZ GS, SIQUEIRA EJ, OLIVEIRA MP. A new technique for reconstruction of lower-lip and labial commissure defects: a proposal for the association of Abbe-Estlander and vermilion myomucosal flap techniques. Oral Surg Oral Med Oral Pathol Oral Radiol, 2013; 115(6):724-30.

2. BARTLETT G, MANSOOR J. Articaine buccal infiltration vs lidocaine inferior dental block - a review of the literature. Br Dent J, 2016; 12;220(3):117-20

3. COATES ML, CARRIE S. A local safety standard for invasive procedures for out-patient endonasal procedures performed under local anaesthetic: a template from Newcastle upon Tyne hospitals. J Laryngol Otol, 2019;133(5):441-444.

4. EBRAHIMI A, MAGHSOUDNIA GR, ARSHADI AA. Prospective comparative study of lower lip defects reconstruction with different local flaps. J Craniofac Surg, 2011; 22(6):2255-9.

5. ESPITALIER F, DRÉNO B, MALARD O. Karapandzic flap for reconstruction of extensive defects of the lower lip. Rev Laryngol Otol Rhinol (Bord), 2013;134(4-5):199-202.

6. FOWLER S, et al. Anesthetic Success of an Inferior Alveolar Nerve Block and Supplemental Articaine Buccal Infiltration for Molars and Premolars in Patients with Symptomatic Irreversible Pulpitis. J Endod, 2016; 42(3):390-2.

7. HARRIS L, HIGGINS K, ENEPEKIDES D. Local flap reconstruction of acquired lip defects. Curr Opin Otolaryngol Head Neck Surg, 2012; 20(4):254-61.

8. KANAA MD, WHITWORTH JM, MEECHAN JG. A comparison of the efficacy of $4 \%$ articaine with 1:100,000 epinephrine and $2 \%$ lidocaine with 1:80,000 epinephrine in achieving pulpal anesthesia in maxillary teeth with irreversible pulpitis. J Endod, 2012; 38(3):279-82.

9. KHOURY J, GRANT T. Neural blockade anaesthesia of the mandibular nerve and its terminal branches: rationale for different anaesthetic techniques including their advantages and disadvantages. Journal of Anesthesiology Research and Practice, 2011; 30:74-23.

10. KHOURY JN, et al. Applied anatomy of the pterygomandibular space: improving the success of inferior alveolar nerve blocks. Aust Dent J, 2011;56(2):112-21. 
11. KUNG J, MCDONAGH M, SEDGLEY CM. Does Articaine Provide an Advantage over Lidocaine in Patients with Symptomatic Irreversible Pulpitis? A Systematic Review and Meta-analysis. J Endod, 2015;41(11):1784-94.

12. LUBEK JE, ORD RA. Lip reconstruction. Oral Maxillofac Surg Clin North Am, 2013; 25(2):203-14.

13. MALAMED SF. Is the mandibular nerve block passé? Journal of the American Dental Association, 2011; 142:3-7.

14. RENTON T, et al. Trigeminal nerve injuries in relation to the local anaesthesia in mandibular injections. British Dental Journal, 2010; 209(9):15

15. SPIVAKOVSKY S. Injectable local anaesthetic agents for dental anaesthesia. Evid Based Dent, 2019;20(2):42-43.

16. TANNER RB, HUBBELL JAE. A Retrospective Study of the Incidence and Management of Complications Associated With Regional Nerve Blocks in Equine Dental Patients. J Vet Dent, 2019; 36(1):40-45.

17. UCHIKAWA Y, et al. Wing flap reconstruction for large defects of the lower lip. J Plast Reconstr Aesthet Surg, 2012; 65(12):1725-8.

18. UGLESIC V, et al. Combined Karapandzic-Abbé/Estlander/Stein flap for subtotal and total lower lip reconstruction. J Plast Reconstr Aesthet Surg, 2019; 72(3):484-490.

19. WONG G, et al. A Tale of Two Teaching Methods: Students' Clinical Perspectives on Administering Dental Local Anesthetics. J Dent Educ, 2019; 28:019.171

20. YE W, et al. Application of modified Karapandzic flaps in large lower lip defect reconstruction. J Oral Maxillofac Surg, $2014 ; 72(10): 2077-82$. 